\title{
Comparison of the Clinical Effect of Open Surgery and Endoscopic Surgery for Thyroid Carcinoma
}




\section{Yin et al.: Comparison of open surgery and endoscopic surgery for thyroid carcinoma}

To compare the therapeutic effects of open surgery and endoscopic surgery for thyroid carcinoma, 160 thyroid carcinoma patients treated in Jilin Cancer Hospital from June 2014 to April 2018 were selected as subjects and randomized into the study and the reference groups, with 80 cases in each group. The reference group was subjected to open surgery, while the study group had endoscopic surgery and the therapeutic outcome of the 2 groups was compared. The surgical indices of the 2 groups used for comparison included, operation time, intraoperative bleeding, surgical incision length and length of stay. Results indicated a significant advantage in the study group over the reference group. Degree of pain was evaluated using the visual analog scale and this score was significantly lower in the study group. The incidence of adverse reactions was significantly lower in the study group relative to the reference group. Endoscopic surgery appeared to provide better results for thyroid carcinoma patients with better safety and reliability.

Key words: Thyroid carcinoma, open surgery, endoscopic surgery, clinical efficacy

Thyroid carcinoma as a common thyroid malignancy accounts for about $1 \%$ of systemic malignancies[1]. Except medullary carcinoma, many thyroid carcinomas are produced in the follicular epithelial cells. Studies have shown that the numerous factors that contribute to thyroid carcinoma are closely related to regions, races, and gender. According to survey statistics, US has a high incidence of thyroid carcinoma. The 19902015 period witnessed increased annual incidence of thyroid carcinoma by more than 3 fold and the trend is still growing year by year[2,3]. China's statistics show that there are about $0.8-0.9 / 100000$ men and 2.0-2.2 $/ 100000$ women with thyroid carcinoma. The incidence of thyroid carcinoma is on the rise owing to factors such as environmental deterioration, accelerated pace of life and changes in dietary structure[4,5]. The thyroid gland is located under the thyroid cartilage of the human neck and on both sides of the trachea. Shaped like a butterfly, it is like a shield and thus acquires its name. The thyroid is divided into left and right lobe and isthmus. The left and right lobe are located on both sides of lower part of the throat and the upper part of the organ. The upper end reaches the midpoint of the thyroid cartilage, and the lower end reaches the sixth tracheal ring, sometimes to the suprasternal fossa or substernal area. The pathogenesis of thyroid carcinoma (fig. 1) is currently unclear, but it is generally believed to be linked with such factors as oncogenes and growth factors, ionizing radiation, genetic factors, iodine deficiency and estrogen. Thyroid carcinoma

*Address for correspondence E-mail: 2261206561@qq.com patients have severely degraded quality of life, which affects normal work, so it is essential to apply optimal treatment regimen to control disease progression and minimize recurrence rates so that patients have higher quality of life. Traditional surgical treatment is the open surgery. With the advancement of medical technology, endoscopic surgery has been widely employed to treat thyroid carcinoma, with good results. This study examines and compares the clinical effects of open surgery and endoscopic surgery for thyroid carcinoma, and provides the following report[6-10]. A total of 160 patients treated in Jilin Cancer Hospital from June 2014 to April 2018, who were clearly diagnosed with thyroid carcinoma (fig. 2) were enrolled as study subjects. Both the patient and family members have the right to know and signed the formal informed

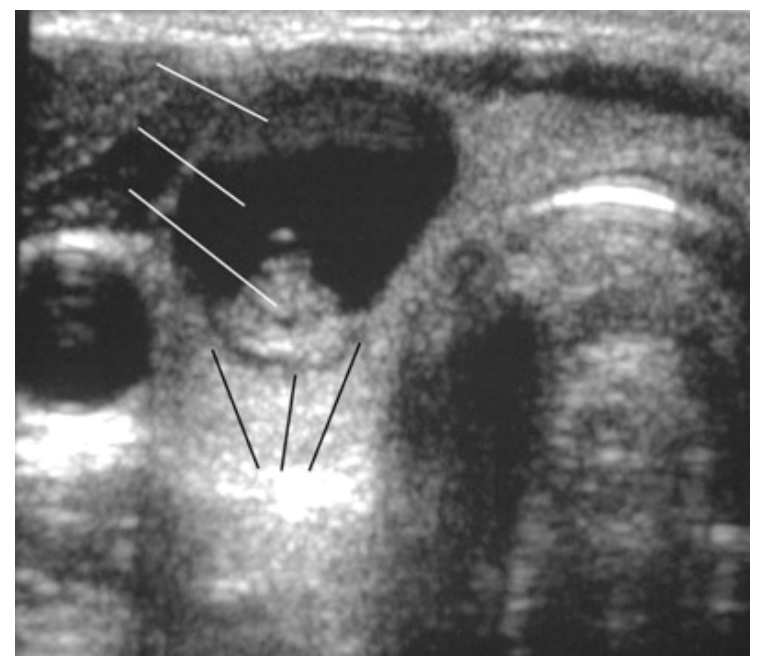

Fig. 1: Ultrasound image of thyroid carcinoma 
consent. The study was approved by the hospital ethics committee. Patients were randomized into the study group and the reference group, with 80 cases in each group. The study group consisted of 10 males and 70 females in the age range of 22-70 y, with an average age of $40.8 \pm 2.9 \mathrm{y}$. The tumor diameter was between $0.4-1.0 \mathrm{~cm}$, with an average diameter of 0.8 $\pm 0.1 \mathrm{~cm}$. The reference group consisted of 8 males and 72 females in the age range of $24-70 \mathrm{y}$, with an average age of $42.6 \pm 2.6 \mathrm{y}$. The tumor diameter was between $0.5-1.1 \mathrm{~cm}$ with an average diameter of $0.7 \pm 0.2 \mathrm{~cm}$. The demographic data of the 2 groups is quite comparable. The reference group was subjected to traditional open surgery. Local anesthesia was given at the neck position and clear mark was made at approximately $1.7 \mathrm{~cm}$ from sternoclavicular joint for parallel lateral incision. The incision extended all the way to the sternomastoideus muscle, shifted to the underlying part of the hyoid bone, and then to the upper end of the sternoclavicular joint. The tumor in the lesion area was excised and a drainage tube was placed to prevent infection. The study group was subjected to endoscopic surgery. Local anesthesia was given at the neck position, clear mark was made at $1.5 \mathrm{~cm}$ above the clavicle and surgical entry point was scientifically selected. Adrenaline was injected into the subcutaneous portion of the incision site. The subcutaneous tissue was cut layer by layer, the connective tissue and the subcutaneous tissue of the muscle group were separated, and the white line of the neck was cut to ensure a complete musculiossis hyoidei and thyroid muscle. The bilateral parts were dragged using leather forceps to clearly expose the thyroid area. Under endoscopy, the size, location, shape, and extent of the lesion were closely observed and then the lesion was completely removed. Strict hemostasis was performed, incision was closed layer by layer and pressure dressing was given. Corresponding antiinfective treatment was provided after the surgery. The surgical indices of the 2 groups were recorded, including operation time, intraoperative bleeding amount, surgical incision length, length of stay. The degree of pain of each patient was evaluated objectively using visual analog scale (VAS) with the highest score of 10 points and the lowest score of 0 . A lower degree of pain carries a lower score. In addition, the incidence of adverse reactions in patients was recorded. Statistical analysis software used was SPSS21.0. The data was expressed as mean \pm standard deviation, t-test was used for comparing the groups; the count data was expressed by natural number (n) and percent $(\%)$, and $\chi 2$ was used for comparing between groups. $\mathrm{P}<0.05$ indicates statistical significance

Table 1 showed the surgical indices of the 2 groups. On comparison of these indices the study group significantly had more advantage over the reference group $(\mathrm{P}<0.05)$. Table 2 showed the VAS scores indicating the degree of pain of the patients of both groups. Results indicated that the pain score is significantly lower in the study group compared to the reference group at 24 and $48 \mathrm{~h}$ after surgery $(\mathrm{P}<0.05)$. The ultrasonography findings of one patient in the study group before and after treatment are shown in fig. 3. Table 3 listed the incidence of adverse reactions in the 2 groups and the data clearly showed that the incidence of adverse reactions is significantly lower in the study group than in the reference group $(\mathrm{P}<0.05)$.

Consensus has not yet been reached on what causes thyroid carcinoma. Studies have shown that food, stimulation and abnormal levels of hormones inside the body are important factors in the pathogenesis[11]. Endoscopic surgery has been widely used in the treatment of thyroid carcinoma in the context of continuous development of minimally invasive techniques. Endoscopic surgery has many advantages in thyroid carcinoma treatment such as minimized

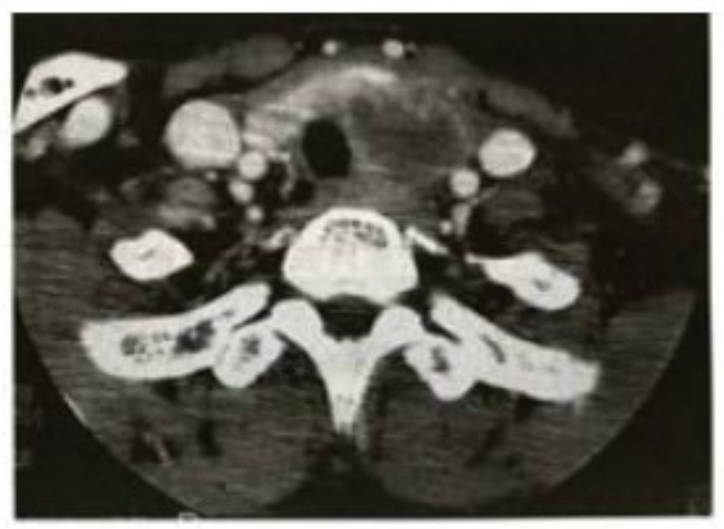

Fig. 2: CT image of a patient with thyroid carcinoma

TABLE 1: COMPARISON OF SURGICAL INDICATORS BETWEEN THE TWO GROUPS

\begin{tabular}{|c|c|c|c|c|c|}
\hline Group & Number of cses & Operation time $(\min )$ & $\begin{array}{c}\text { Intraoperative } \\
\text { bleeding amount }(\mathrm{ml})\end{array}$ & $\begin{array}{c}\text { Surgical incision } \\
\text { length }(\mathrm{cm})\end{array}$ & $\begin{array}{l}\text { Length of stay } \\
\text { (d) }\end{array}$ \\
\hline study group & 80 & $78.09 \pm 10.4$ & $18.60 \pm 10.29$ & $3.26 \pm 0.28$ & $4.02 \pm 1.98$ \\
\hline reference group & 80 & $105.8 \pm 11.2$ & $55.70 \pm 12.47$ & $15.28 \pm 0.26$ & $8.75 \pm 2.02$ \\
\hline $\mathrm{t}$ & & 10.29 & 15.69 & 8.33 & 9.26 \\
\hline$P$ & & $<0.05$ & $<0.05$ & $<0.05$ & $<0.05$ \\
\hline
\end{tabular}


www.ijpsonline.com

TABLE 3: COMPARISON OF INCIDENCE OF ADVERSE REACTIONS IN THE TWO GROUPS

\begin{tabular}{lccccc}
\hline Group & Number of cases & Hoarseness & Dyspnea & Incision infection & Incidence of adverse reactions \\
\hline Study & 80 & 1 & 1 & 0 & $2(2.50)$ \\
Reference & 80 & 5 & 4 & 4 & $13(16.25)$ \\
$X^{2}$ & & & & 9.62 \\
$P$ & & & $<0.05$ \\
\hline
\end{tabular}

TABLE 2: COMPARISON OF PAIN SCORES BETWEEN THE TWO GROUPS

\begin{tabular}{lccc}
\hline Group & $\begin{array}{c}\text { Case } \\
\text { number }\end{array}$ & $\begin{array}{c}24 \mathrm{~h} \text { after } \\
\text { surgery }\end{array}$ & $\begin{array}{c}48 \mathrm{~h} \text { after } \\
\text { surgery }\end{array}$ \\
\hline Study group & 80 & $3.20 \pm 0.78$ & $2.90 \pm 0.26$ \\
Reference group & 80 & $6.29 \pm 0.90$ & $4.58 \pm 0.30$ \\
$\mathrm{t}$ & & 4.30 & 3.29 \\
$P$ & & $<0.05$ & $<0.05$ \\
\hline
\end{tabular}
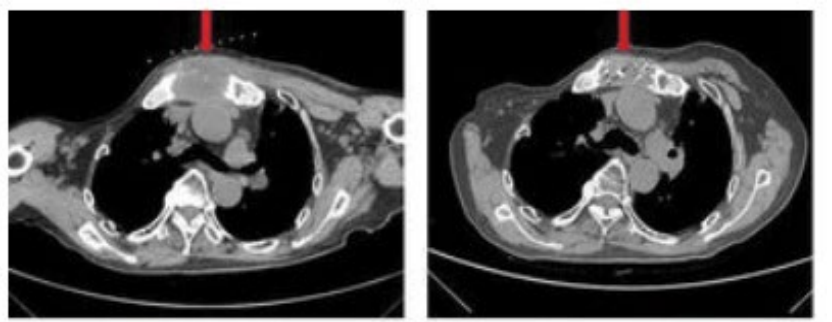

Fig. 3: Ultrasonography findings of one patient in the study group before and after treatment

trauma, reduced hospitalization time, fast postoperative recovery and with absence of scars accepted more by patients[12,13].

Endoscopic thyroidectomy, as an advanced medical technique with important range of applications, is suitable for patients with benign thyroid lesions and relatively small tumors. If the tumor diameter is large, other operations should be considered instead[14-18]. Young and middle-aged women with high incidence of thyroid carcinoma have greater requirement for cosmetic surgery. In the traditional open surgery method, the opening is 2-finger distance from the sternum, generally leaves scars of about $6 \mathrm{~cm}$ or longer, which affects the aesthetics. However, endoscopic surgery significantly reduces surgical incision length by taking anterior sternum as the incision position. The small surgical incision meets patients' aesthetic needs[19-21]. In addition, with continuous innovation in endoscopic techniques and minimally invasive surgical instruments, these surgical approaches have increased in number, of which, anterior cervical approach and exterior cervical approach are commonly used. Compared with traditional open surgery, anterior cervical approach could avoid the influence of clavicle and sternum to enable direct observation of operation field, especially suitable for thyroid lobectomy, total thyroidectomy, central lymph node dissection and neck dissection. According to the present study results, comparison of surgical indices that included operation time, intraoperative bleeding, surgical incision length, length of stay between the study group subjected to endoscopic surgery and the reference group operated with traditional open surgery showed significant advantage for the study group over the reference group $(\mathrm{P}<0.05)$. Patient pain evaluation using VAS clearly demonstrated that the study group has a significantly lower score than the reference group $(\mathrm{P}<0.05)$. The incidence of adverse reactions is also significantly lower in the study group than in the reference group $(\mathrm{P}<0.05)$. These results clearly demonstrated the ideal nature of endoscopic surgery for thyroid carcinoma. In summary, endoscopic surgery for thyroid carcinoma could achieve better outcomes with higher safety and reliability as well as better cosmetic results. Therefore, it is worth of extensive promotion and application.

\section{REFERENCES}

1. Huo, Y. Comparison of clinical effects between open surgery and endoscopic surgery for thyroid carcinoma. Chinese J Mod Drug Appl, 2017;11(11):71-2.

2. Su Z, Huang H, Liang ZJ. Comparative clinical study on the effect of microwave ablation and endoscopic surgery for benign thyroid nodules. J Clin Med Literature 2017;4(24):4627-9.

3. Zhan SQ. Analysis of the effect of open surgery and endoscopic surgery on thyroid carcinoma. China Modern Medicine 2015;22(32):69-70.

4. Martinod K, Demers M, Fuchs TA, Wong SL, Brill A, Gallant $\mathrm{M}$, et al. Neutrophil histone modification by peptidylarginine deiminase 4 is critical for deep vein thrombosis in mice. Proc Natl Acad Sci U S A 2013; 110(21):8674-9.

5. Wilson TJ, Stetler Jr WR, Fletcher JJ. Comparison of catheterrelated large vein thrombosis in centrally inserted versus peripherally inserted central venous lines in the neurological intensive care unit. Clin Neurol Neurosurg 2013;115(7):87982.

6. Gao W, Wang Y, Wang W, Li Shi. The first multiplication atom-bond connectivity index of molecular structures in drugs. Saudi Pharm J 2017; 25(4):548-55.

7. Wang L, Ge S, Liu Z, Zhou Y, Yang X, Yang W, et al. Properties of antibacterial bioboard from bamboo macromolecule by hot press. Saudi J Biol Sci 2018;25(3):465-8.

8. Azemi AK, Abd Rahim MH, Mamat SS. Antiulcer activity of methanol-chloroform extract of Channa striatus fillet. Pak J Pharm Sci 2018;31(1):143-51.

9. Aleanizy FS, Alqahtani FY, Shazly G. Measurement and evaluation of the effects of $\mathrm{p}$ gradients on the antimicrobial 
and antivirulence activities of chitosan nanoparticles in Pseudomonas aeruginosa. Saudi Pharm J 2018; 26(1): 79-83.

10. Ahmadi M, Javedani M, Ghiasi B. Investigation of the relationship between phase angle and micro-albuminuria in type 2 diabetic patients with a history of more than 5 years of the disease in Ilam Province, Iran. Acta Medica Mediterranea 2017;33(2):351-7.

11. Wang C, Wang L, Zhang Y, Chen M. A novel approach for assessing the progression of deep venous thrombosis by area of venous thrombus in ultrasonic elastography. Clin Appl Thromb Hemost 2014;20(3):311-7.

12. Ding GP. Clinical effect comparison of open surgery and endoscopic surgery for thyroid carcinoma. Chin J Clini Rational Drug Use 2016;9(18):108-9.

13. Wang G. Observation on the effect of open surgery and endoscopic surgery for thyroid carcinoma. Chi J Mod Drug Appl 2017;11(23):29-30.

14. Galanaud JP, Holcroft CA, Rodger MA, Kovacs MJ, Betancourt MT, Wells PS, et al. Predictors of post-thrombotic syndrome in a population with a first deep vein thrombosis and no primary venous insufficiency. J Thromb Haemost 2013;11(3):474-80.

15. Simsek E, Yesilyurt A, Pinarli F, Eyerci N, Ulus AT. Combined genetic mutations have remarkable effect on deep venous thrombosis and/or pulmonary embolism occurrence. Gene 2014;536(1):171-6.

16. Gao W, Wang Y, Basavanagoud B, Jamil MK. Characteristics studies of molecular structures in drugs. Saudi Pharm J 2017;25(4):580-6.
17. Akici A, Aydin V, Kiroglu A. Assessment of the association between drug disposal practices and drug use and storage behaviors. Saudi Pharm J 2018;26(1):7-13.

18. Golezar E, Mahdiuni H, Nazari A. Different antioxidant activity measurements of the aerial parts of Ferulago angulate, traditional food additives in Iran. Indian J Pharm Sci 2017;79(6): 900-6.

19. Karagoz H, Erden A, Ozer O. The role of blood groups in nonalcoholic fatty liver disease and non-alcoholic steatohepatitis. Acta Medica Mediterranea 2017;33(2):205-10.

20. Khan A, Iqbal ZA. Clinical study showing altered antioxidants profile in patients with hypertension. Pak J Pharm Sci 2018;31(1):9-18.

21. Xie Y, Ge S, Jiang S. Study On Biomolecules in Extractives of Camellia Oleifera Fruit Shell by GC-Ms. Saudi J Biol Sci 2018;25(2):234-6.

This is an open access article distributed under the terms of the Creative Commons Attribution-NonCommercial-ShareAlike 3.0 License, which allows others to remix, tweak, and build upon the work non-commercially, as long as the author is credited and the new creations are licensed under the identical terms

This article was originally published in a special issue: Special issue on "Animal Models \& Experimental Medicine"

Indian J Pharm Sci 2020:82(1)spl issue4;44-48 